\title{
Resenha: Darwin, o Comportamento Humano e as Emoções
}

\author{
Maria Angela Guimarães Feitosa ${ }^{1}$ \\ Universidade de Brasília
}

\section{Book Review: Darwin, Human Behavior and Emotions}

\begin{abstract}
Charles Darwin. The Expression of the Emotions in Man and Animals. Terceira edição, 1998. Com uma Introdução, Posfácio e Comentários por Paul Ekman. New York/ Oxford: Oxford University Press. (509 páginas, 40 ilustrações, ISBN 0-19-511271 -

7, preço de capa US\$30,00)
\end{abstract}

Ao desenvolver sua teoria da evolução, Darwin explicitou, em The Origin of Species, a evolução da morfologia e da fisiologia dos organismos. No entanto, já nessa obra, sinalizava sua preocupação em estender sua teoria para o comportamento humano. Ele afirma

"No futuro vejo campos abertos para pesquisas muito mais importantes. A Psicologia será firmemente baseada na fundação já bem assentada pelo Sr. Herbert Spencer, a da aquisição necessária de cada capacidade e poder mental por gradação. Muita luz surgirá acerca da origem do homem e sua história." (1859/1958, pg. 449).

[Esta referência de Darwin sugere seu contato com Princípios de Psicologia, publicado por Spencer em 1855, embora Boring (1950) situe na segunda edição desta obra de Spencer (cujos dois volumes foram publicados respectivamente em 1870 e 1872) a explicitação mais clara de sua contribuição para o associacionismo evolucionário.] Só em seus escritos posteriores Darwin efetivamente explicita suas concepções sobre a evolução do comportamento. The Descent of Man, e The Expression of the Emotions in Man and Animals, são as duas obras em que estas idéias ocupam espaço próprio.

A primeira edição de The Expression of the Emotions in Man and Animals foi publicada na Grã Bretanha em 1872, um ano depois da publicação de Descent of Man e treze anos depois de The Origin of Species. A despeito do interesse de Darwin em efetuar modificações ao texto, uma segunda edição só foi publicada em 1889, sete anos após sua morte, sob a supervisão de Francis Darwin, filho de Charles, o qual incluiu algumas das modificações indicadas por Charles. Reimpressões subsequentes, inclusive a edição de 1965 da Universidade de Chicago, que serviu de base à recente tradução da obra para o português pela Companhia das Letras, originaram-se da primeira edição inglesa. A organização de uma terceira edição em língua inglesa foi confiada a Paul Ekman, autoridade nas áreas de comunicação não verbal e de expressão facial das emoções em particular, cujo trabalho meticuloso acrescentou valor especial a este clássico por si só importante para o estudioso do comportamento.

1 Endereço: Universidade de Brasília, Instituto de Psicologia, Departamento de Processos Psicológicos Básicos, CEP: 70910-900 Brasília, DF. E-mail: afeitosa@unb.br
A capa do livro traz a audaciosa expressão "Edição Definitiva" logo abaixo do título. Ekman justifica esta liberdade da Oxford University Press, explicando no prefácio que esta edição

"contém as mudanças que Charles Darwin havia desejado, mas que seu filho não incluiu na segunda edição. Tem mais do texto de Darwin e mais de suas ilustrações no livro do que qualquer edição anterior. Com base na correspondência entre Darwin e seu Editor, suas cartas a outros, e anotações em seu próprio exemplar de Expressões nos arquivos da Biblioteca da Universidade de Cambridge, acredito que esta edição está como Darwin gostaria." (p. xiv)

Das 509 páginas da obra, 360 são ocupadas com o texto de Darwin; as demais 149 refletem o trabalho editorial de Ekman.

O livro está organizado em três seções principais. A primeira delas contém um prefácio à terceira edição, onde Ekman tece uma série de considerações técnicas sobre a organização desta edição; a reprodução do curto prefácio à segunda edição, escrito por Francis Darwin; e uma Introdução à Terceira Edição, em que Ekman usa parte substancial do espaço argumentando porque, tendo The Expression of the Emotions sido um sucesso de venda logo após o lançamento, caiu no esquecimento por 90 anos e só nas últimas três décadas foi redescoberto. Ele identifica cinco críticas centrais ao trabalho de Darwin: de recurso ao antropomorfismo; de uso de evidência anedótica; de adoção do princípio lamarckiano de hereditariedade de características adquiridas; de negligência para com o valor comunicativo na origem das expressões emocionais; e, o que Ekman considera especialmente devastador, de confronto aos dogmas vigentes, ao propor que as expressões são inatas e de que estes sinais de nossas emoções são produto de nossa evolução. Ao avaliar essas críticas ele parcialmente as endossa, parcialmente contra argumenta em função de características do método de Darwin que permitiriam minimizar seu impacto, e parcialmentre as reinterpreta, à luz do Zeitgeist político. $\mathrm{Na}$ avaliação de Ekman a renovação no interesse pelo livro de Darwin precisou esperar a ação conjunta de alguns fatores que levaram a um entendimento mais abrangente sobre a determinação do comportamento humano: a forte evidência produzida nas décadas de 60 e 70 acerca da universalidade das expressões, o desencanto com as limitações do behavio- 
rismo e a emergência da legitimidade de se estudar pensamentos e idéias, com a ciência cognitiva. Ainda segundo Ekman, foram influentes o crescimento rápido da genética do comportamento, o surto de conhecimento sobre o cérebro, o Projeto Genoma Humano, e o desvelar contínuo de como muitas diferenças individuais têm base genética.

O texto de Darwin na íntegra compõe a segunda seção. Inclui a Introdução à Primeira Edição, os três capítulos iniciais sobre os princípios gerais de expressões, três capítulos dedicados à explicitação das modalidades de expressões, sete capítulos sobre as expressões de diferentes emoções no homem e o capítulo final de conclusão. Nesta seção ilustrações foram aproximadas do texto a que se referem; foram acrescentadas as ilustrações que Darwin usou em sua pesquisa, mas omitiu da primeira edição possivelmente por razões de custo de impressão e que, apesar de terem sua incorporação a uma segunda edição planejada, não o foram por Francis. Desta reconstrução resultou que 32 figuras acompanham o texto de Darwin e 8 ilustrações acompanham as seções complementares; além disto foi identificada a efetiva autoria dos acréscimos na segunda edição (alguns de Charles, outros de Francis).

Na terceira seção encontram-se um capítulo por Ekman, onde este discute a questão da universalidade da expressão emocional. Nos apêndices que se seguem encontramos o obituário de Charles Darwin, escrito por Thomas H. Huxley para a revista Nature; os registros de Ekman sobre as modificações ao texto, os comentários de Phillip Prodger e de Paul Ekman sobre as fotografias que contribuíram para o trabalho de The Expression of the Emotions, bem como sobre o que delas se transformou em ilustração nas diferentes edições; o índice remissivo da primeira edição. Concluindo, encontram-se as notas de Ekman e o índice à presente obra.

No texto principal de The Expression of the Emotions, Darwin expõe seus três princípios gerais "explicativos das expressões e gestos usados involuntariamente pelo homem e pelos animais inferiores, sob a influência de várias emoções e sensações" (p. 33). São eles o princípio dos hábitos associados de serventia ["ações complexas de serventia direta ou indireta em certos estados da mente, a fim de aliviar ou gratificar certas sensações, desejos, etc" (pg 34)]; o princípio da antítese, de acordo com o qual "certos estados da mente levam a certas ações habituais, que são de serventia, mas quando um estado mental diretamente oposto é induzido, há uma forte tendência involuntária do desempenho de movimentos de natureza diretamente oposta" (pg 34); e $o$ princípio de ação direta do sistema nervoso, de acordo com o qual ações expressivas de certos estados mentais são o resultado direto da constituição do sistema nervoso, e são independentes de desejo e em grande parte de hábito.

A apresentação destes princípios (capítulos I a III) é cuidadosamente acompanhada de inúmeros exemplos reunidos por Darwin a partir de suas observações, e por notas com comentários de Darwin e dos dois organizadores ( Francis Darwin e Paul Ekman). Os meios gerais de expressão são a seguir apresentados para os animais (capítulos IV e V) e para o homem (capítulo VI), com deliberado esforço em mostrar como as expressões deste partilham características com aqueles. Nos capítulos VII a XIII Darwin trata de diferentes categorias de emoções no homem e explora sua universalidade a partir de exemplos colhidos em culturas diferentes. Nos comentários finais Darwin expressa sua satisfação com a quantidade e a consistência da evidência arrebanhada acerca da efetividade dos três princípios gerais da expressão das emoções, mas se mostra reticente quanto à evidência de que o reconhecimento das expressões seja inato ou mesmo efetivo. Desta forma, ele contesta seu valor comunicativo, uma questão que foi contemporaneamente retomada, inclusive por Ekman.

Das partes que se seguem ao texto central de Darwin, duas merecem atenção especial: o Posfácio, pelo seu valor conceituai, e o Apêndice III pelo seu valor metodológico. No Posfácio, Ekman presenteia o leitor com sua visão da questão da universalidade da expressão emocional, relatando como o movimento eugênico e a preocupação com sua disseminação acirrou a controvérsia sobre Darwin e mais especificamente sobre a universalidade das expressões emocionais, enquanto suporte para a tese central de que os seres humanos se originaram de um progenitor comum. Ekman desnuda o bastidor das motivações e dos fatores históricos e sociais que influenciaram os antagonismos entre Margaret Mead, Gregory Bateson, Ray Birdwhistell, Silvan Tomkins e ele próprio, num relato importante para uma análise do relativismo cultural. Esclarece também a distinção contemporânea entre programas genéticos "abertos" e "fechados" de controle de comportamento, uma distinção que só é clara no entendimento contemporâneo (cf. Mayr, 1982) de como diferentes tipos de comportamento desempenham papéis diferentes na evolução.

No Apêndice III, os comentários de Prodger permitemnos compreender como Darwin chegou a cada ilustração de sua obra, narrando e justificando com detalhe as decisões técnicas envolvidas para atender à preocupação de Darwin de que as fotografias contivessem o máximo de informação fatual. São por si só um depoimento sobre o nascimento da aplicação da fotografia à pesquisa científica. Prodger vem à defesa de Darwin na crítica que este sofreu à sua falta de distinção entre evidência e ilustração, resgatando mais este papel histórico do trabalho, um dos primeiro livros científicos publicados com ilustrações fotográficas, produzido com enormes limitações técnicas relacionadas à incipiência da técnica fotográfica. Apresenta-nos os fotógrafos colaboradores de Darwin na tarefa de produzir as ilustrações e argumenta que o livro não poderia se conformar a regras contemporâneas sobre fotografia científica porque ele foi parte da criação destas regras. Nesta seção é especialmente interessante a descrição da parceria de Darwin com o fotógrafo Oscar Reijlander.

Prodger e Ekman são responsáveis por observações sobre a orientação das gravuras no Apêndice IV, um preciosismo de registro sem dúvida importante para o estudioso da área, em virtude do conhecimento mais recente de que a expressão facial da emoção mostra assimetria. Para concluir a análise da ilustração da obra, Prodger se dá à tarefa, 
no Apêndice V, de estabelecer a correspondência das ilustrações da presente edição com as das edições anteriores do livro, bem como o registro sistematizado dos autores das ilustrações e a modalidade de registro usada.

The Expression of the Emotions in Man and Animals deveria ser lido por todo estudioso que contempla a hipótese de que uma perspectiva evolucionária ao comportamento possa ser um referencial unificador para a teoria psicológica, pela sua centralidade no desenvolvimento deste tipo de proposição. A leitura dos clássicos é importante para uma compreensão clara da evolução das idéias em ciência. Ajuda-nos a entender como alguns problemas que tomamos como novos ou originais em verdade já haviam sido postos; a entender a origens de conceitos contemporâneos; e também a compreender as decisões que os cientistas tomaram a respeito de o que pesquisar, e como e quando publicar. Ekman não só nos proporciona nesta terceira edição o con- junto mais fidedigno dos fatos sobre a obra de Darwin mas, através de um grande número de notas, guia o leitor na apreciação crítica do enorme empreendimento de construção do conhecimento por ele realizado - tanto em sua genialidade quanto em seus equívocos e limitações.

\section{Referências}

Boring, E.G. (1950). A history of experimental psychology ( $\left.2^{\mathrm{a}} \mathrm{ed}.\right)$. Englewood Cliffs, N. J.: Prentice-Hall. (Originalmente publicado em 1929)

Darwin, C. (1958). The origin of species. New York: The New American Library of World Literature. (Originalmente publicado em 1859)

Mayr, E. (1982). The growth of biological thought. Cambridge, Mass: Harvard University Press.

Recebido em 14.03.2000

Primeira decisão editorial em 11.05.2000

Versãofinal em 16.05.2000

Aceito em 12.06.2000 